\title{
Application of Selected Artificial Intelligence Methods in a System Predicting the Microstructure of Compacted Graphite Iron
}

\author{
Barbara Mrzygłód (D), Grzegorz Gumienny, Dorota Wilk-Kołodziejczyk, and Krzysztof Regulski
}

\author{
(Submitted September 28, 2018; in revised form December 29, 2018; published online February 19, 2019)
}

\begin{abstract}
Intelligent computing tools such as artificial neural network and fuzzy logic are used as predictive modeling tools. The use of these methods, combined with model experimental results, may be an excellent predictive tool, allowing us to forecast the microstructure of the tested cast iron at the level of computer simulation. In this study, the reference training cases collected in one database were used to determine the parameters of the neuro-fuzzy ANFIS model. They mainly include the results of observations and measurements of the content of individual microstructural constituents of the compacted graphite iron, examined as a function of the content of individual alloy additives (molybdenum, nickel and copper introduced in various proportions). The training process of such a fuzzy inference system is done by constantly changing its parameters (parameters of the membership function) and determining new rule conclusions as a result of presenting individual case examples from the training sample. The conducted research has shown the possibility of applying the ANFIS model as a tool to control the chemical composition of compacted graphite iron in the production of castings with high-strength parameters.
\end{abstract}

Keywords ANFIS, compacted graphite iron, data mining, foundry industry, information technology

\section{Introduction}

Compacted graphite iron (CGI) having a specific graphite morphology with a large contact surface with the matrix is a unique casting material. It is characterized by a tensile strength range of $300-500 \mathrm{MPa}$ at corresponding elongation of $2-0.5 \%$, respectively. Compared to gray cast iron, this material demonstrates higher strength properties and higher elongation. The matrix microstructure is less dependent on the casting wall thickness. In comparison with spheroidal graphite cast iron, cast iron with compacted graphite exhibits lower coefficient of thermal expansion, higher thermal conductivity, better resistance to thermal shocks, higher vibration damping capacity and better castability. The representative microstructure of the spheroidal graphite cast iron as well as CGI is presented in Fig. 1(a) and (b).

This article is an invited submission to JMEP selected from presentations at the 73rd World Foundry Congress and has been expanded from the original presentation. 73WFC was held in Krakow, Poland, September 23-27, 2018, and was organized by the World Foundry Organization and Polish Foundrymen's Association.

Barbara Mrzyglód, Dorota Wilk-Kolodziejczyk, and Krzysztof Regulski, Department of Applied Computer Science and Modelling, AGH University of Science and Technology, Al. Mickiewicza 30, 30-059 Kraków, Poland; and Grzegorz Gumienny, Politechnika Lodzka, Wydzial Mechaniczny, Lodz, Poland. Contact email:mrzyglod@agh.edu.pl.
It results from Fig. 1 that CGI has a greater tendency to form ferrite in comparison with nodular cast iron.

All above-mentioned advantages predestine the material for a variety of applications. CGI is mainly used for the construction of combustion engine blocks, exhaust manifolds, etc. Interesting properties of this type of cast iron are the reason for intensive research and numerous publications (Ref 1-10). There are few publications, however, concerning the influence of alloy additives on the microstructure and properties of CGI (Ref 11-13). By changing the chemical composition of this cast iron, it is possible to modify its microstructure and consequently its properties. There are many available publications which describe how to obtain an ausferrite in CGI. Then the resulting cast iron grade is referred to as austempered vermicular iron (AVI) or carbidic austempered vermicular iron (CAVI) (Ref 14-17). The ausferrite is a mixture of bainitic ferrite and high-carbon stabilized austenite. To produce ausferrite, an austempering process is required. There is also an alternative way to obtain this constituent, i.e., by modification of the cast iron chemical composition, using for this purpose molybdenum, copper and nickel added in appropriate proportions.

The typical matrix microstructure of the non-alloyed CGI consists of ferrite and pearlite. The large contact surface of graphite with matrix promotes the ferrite formation in this type of cast iron. In order to increase the tendency toward pearlite formation, copper is usually added to the cast iron, sometimes in combination with nickel (Ref 18). Further increase in the concentration of nickel promotes the formation of martensitic microstructure due to a significant increase in hardenability (Ref 19). Increasing the concentration of nickel above $20 \%$ results in the formation of stable austenite in the matrix. In compacted graphite iron, an ausferritic matrix can also be obtained. It is usually produced as a result of the heat treatment of castings consisting in hardening with isothermal holding. This cast iron is called AVI-austempered vermicular iron. It is 


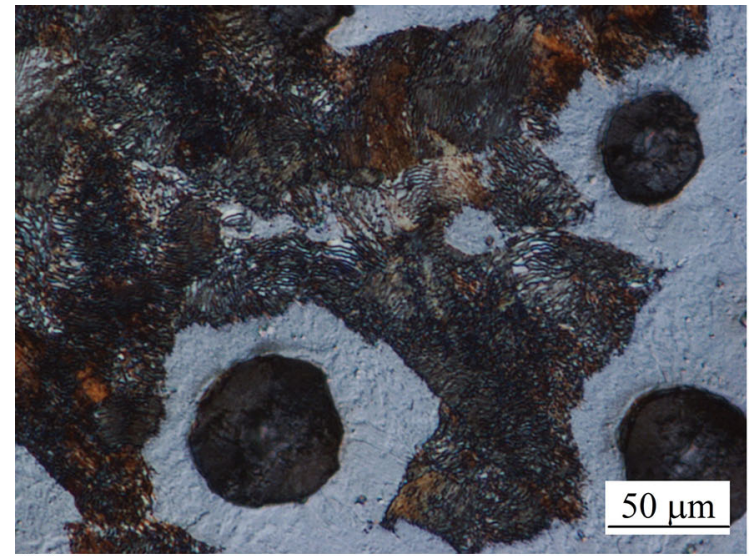

(a)

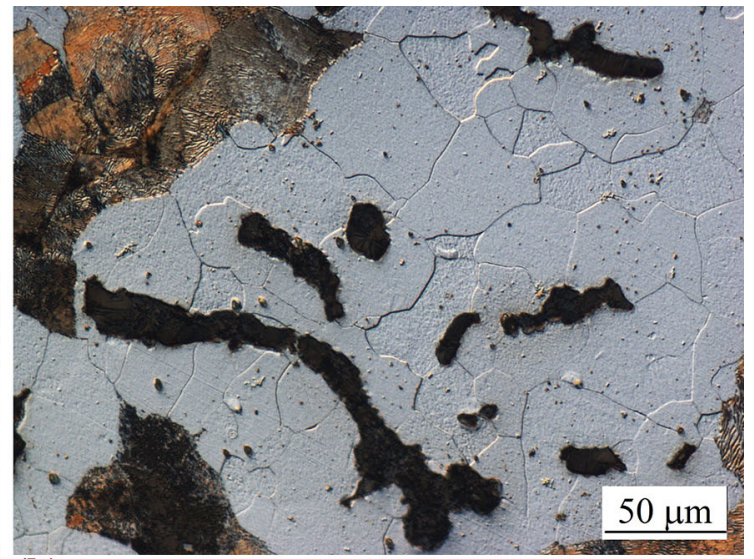

(b)

Fig. 1 The representative microstructure of the non-alloyed spheroidal graphite cast iron (a) and compacted graphite iron (b)

also possible to obtain an ausferritic microstructure in as-cast condition in the cast iron with flake, spheroidal or vermicular graphite (Ref 20-22). This can be achieved by the addition of alloying elements increasing austenite stability but only in the pearlitic range. One of such alloying elements is molybdenum which, added together with nickel or copper, promotes ausferrite formation when the casting is solidifying in the mold. Chromium allows controlling the amount of carbides. At concentrations above $1.5 \%$, it makes cast iron crystallize only in a metastable system, producing the so-called "white cast iron."

As part of many research works carried out by the authors of this work, numerous material experiments were carried out to examine the effect of the content of selected alloying elements on the microstructure of compacted graphite iron. Many years of studies have finally resulted in the development of a database that integrates the results of these studies. In this paper, the results of experiments are collected in a single database, along with the results of observations and measurements of the content of individual constituents of the microstructure of CGI, depending on the content of alloy additives.

Due to the high cost of experimental melts, the use of the adaptive neuro-fuzzy inference system (ANFIS) algorithm (Ref 23-25) has been proposed, by means of which it is possible to predict the microstructural constituents based on the cast iron chemical composition and casting wall thickness.

\section{Source Data}

The database contains the results of examinations and measurements of the content of individual microstructural constituents of the compacted graphite iron (ferrite, pearlite, carbides, martensite, ausferrite and austenite). They are examined as a function of the content of individual alloy additions within the studied range of the chemical composition, including: $\mathrm{Cu}$ content (wt.\%), Ni content (wt.\%) and Mo content (wt.\%), for different casting wall thicknesses (mm). The developed database contains 170 records; its fragment is presented in Fig. 2.

With the integrated knowledge of selected process available in the database, one can attempt to construct algorithms and inference systems that enable automatic processing of this knowledge. As a consequence, it is possible to build computer systems that give the opportunity to create new knowledge without the need to perform additional material experiments.

\section{Research Methodology}

Section 3.1 describes the results of materials research used for the creation of a database which served as a basis for the development of a computer system to examine and predict the quantitative contribution of individual microstructural constituents. Section 3.2 describes the characteristic features of the ANFIS algorithm, which is a formal tool used to build the system.

The decisive influence on the choice of this formalism (which is a combination of fuzzy logic with the methods of training artificial neural networks) had the character of the obtained data, which are the results of experimental measurements and microscopic observations. This information is only representative of some specific cases, and as such is incomplete and burdened with measurement errors, thus yielding only uncertain data. Fuzzy logic finds particular application in the processing of this type of knowledge.

\subsection{Material Experiment}

The chemical composition of the tested cast iron is shown in Table 1. The chemical composition was tested using SPECTROMAXx arc spark OES metal analyzer. Metal was melted in an electric medium-frequency induction crucible furnace of $30 \mathrm{~kg}$ capacity. The vermicularizing treatment of cast iron was done by an Inmold process. The schematic layout of elements in the mold is presented in Fig. 3. For various combinations of alloy additions, the chemical composition enabled obtaining different types of cast iron metal matrix, i.e., ferritic, pearlitic, martensitic, austenitic and ausferritic.

At $1480{ }^{\circ} \mathrm{C}$, the cast iron was poured into a green sand mold with the gating system comprising a spherical reaction chamber of $\phi 85 \mathrm{~mm}$ diameter. In this chamber, Lamet ${ }^{\circledR} 5504$ magnesium master alloy supplied by Elkem Norway was placed. The composition of the master alloy is shown in Table 2. Behind the reaction chamber, there was a mixing chamber. Next, a stepped test casting with the wall thickness of 3, 6, 12 and $24 \mathrm{~mm}$ was 


\begin{tabular}{|c|c|c|c|c|c|c|c|c|c|}
\hline $\mathrm{Cu}$ & $\mathrm{Ni}$ & Mo & thickness & ferrite & pearlite & carbides & martensite & ausferrite & austenite \\
\hline 0 & 9,26 & 0 & 24 & 0 & 0 & 0 & 95 & 0 & 5 \\
\hline 0 & 14,86 & 0 & 3 & 0 & 0 & 0 & 15 & 0 & 85 \\
\hline 0 & 14,86 & 0 & 6 & 0 & 0 & 0 & 21 & 0 & 79 \\
\hline 0 & 14,86 & 0 & 12 & 0 & 0 & 0 & 30 & 0 & 70 \\
\hline 0 & 14,86 & 0 & 24 & 0 & 0 & 0 & 37 & 0 & 63 \\
\hline 0 & 16,53 & 0 & 3 & 0 & 0 & 0 & 7 & 0 & 93 \\
\hline 0 & 16,53 & 0 & 6 & 0 & 0 & 0 & 8 & 0 & 92 \\
\hline 0 & 16,53 & 0 & 12 & 0 & 0 & 0 & 10 & 0 & 90 \\
\hline 0 & 16,53 & 0 & 24 & 0 & 0 & 0 & 11 & 0 & 89 \\
\hline 0 & 21,04 & 0 & 3 & 0 & 0 & 0 & 0 & 0 & 100 \\
\hline 0 & 21,04 & 0 & 6 & 0 & 0 & 0 & 0 & 0 & 100 \\
\hline 0 & 21,04 & 0 & 12 & 0 & 0 & 0 & 0 & 0 & 100 \\
\hline 0 & 21,04 & 0 & 24 & 0 & 0 & 0 & 0 & 0 & 100 \\
\hline 0 & 0 & 1,96 & 3 & 6 & 49 & 45 & 0 & 0 & 0 \\
\hline 0 & 0 & 1,96 & 6 & 18 & 57 & 18 & 0 & 7 & 0 \\
\hline 0 & 0 & 1,96 & 12 & 35 & 20 & 5 & 0 & 40 & 0 \\
\hline 0 & 0 & 1,96 & 24 & 30 & 62 & 3 & 0 & 5 & 0 \\
\hline 0,49 & 0 & 2,42 & 3 & 0 & 0 & 3 & 0 & 97 & 0 \\
\hline 0,49 & 0 & 2,42 & 6 & 0 & 0 & 3 & 0 & 97 & 0 \\
\hline 0,49 & 0 & 2,42 & 12 & 1 & 0 & 4 & 0 & 95 & 0 \\
\hline 0,49 & 0 & 2,42 & 24 & 1 & 1 & 5 & 0 & 93 & 0 \\
\hline 0,98 & 0 & 2,08 & 3 & 0 & 0 & 2 & 0 & 98 & 0 \\
\hline 0,98 & 0 & 2,08 & 6 & 0 & 0 & 1 & 0 & 99 & 0 \\
\hline 0 & 0 & 0 & 24 & 27 & 73 & 0 & 0 & 0 & 0 \\
\hline 0 & 0 & 0 & 3 & 0 & 72 & 28 & 0 & 0 & 0 \\
\hline
\end{tabular}

\begin{tabular}{l|l|l|l} 
& $\cdots$ & $\cdots$ &
\end{tabular}

Fig. 2 A fragment of the developed database

Table 1 Chemical composition of the tested cast iron

\begin{tabular}{lccccccr}
\hline \multicolumn{7}{c}{ Chemical composition, wt.\% } \\
\hline $\mathbf{C}$ & $\mathbf{S i}$ & $\mathbf{M n}$ & $\mathbf{M o}$ & $\mathbf{C u}$ & $\mathbf{N i}$ & $\mathbf{C r}$ & $\mathbf{M g}$ \\
\hline $2.91-3.82$ & $2.28-2.71$ & $0.03-1.31$ & $0-2.44$ & $0-3.80$ & $0-21.04$ & $0-2.81$ & $0.017-0.019$ \\
\hline
\end{tabular}

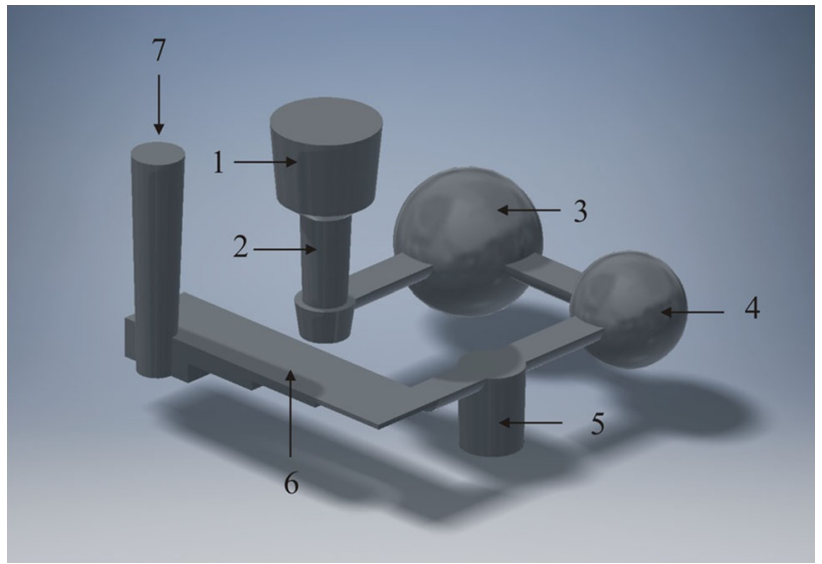

Fig. 3 Schematic layout of elements in the mold: 1-pouring cup, 2-downsprue, 3-reaction chamber, 4-mixing chamber, 5 - control chamber, 6-stepped test casting and 7-flow off

made. All castings were knocked out after cooling to ambient temperature.

Specimens for metallographic tests were cut out from the central part of the stepped casting. Its shape and dimensions are shown in Fig. 4.
Table 2 Chemical composition of the master alloy

\begin{tabular}{lccccc}
\hline \multicolumn{6}{c}{ Chemical composition, wt.\% } \\
\hline Si & Mg & Ca & La & Al & Fe \\
\hline $44-48$ & $5-6$ & $0.4-0.6$ & $0.25-0.40$ & $0.8-1.2$ & Rest
\end{tabular}

The metallographic examinations were carried out under a Nikon Eclipse MA200 optical microscope at a magnification of $500 \times$. Specimens were etched with a $4 \% \mathrm{HNO}_{3}$ solution in $\mathrm{C}_{2} \mathrm{H}_{5} \mathrm{OH}$. The microstructure examined using NIS-Elements $\mathrm{BR}$ image analysis program.

\subsection{Developed Models: ANFIS Algorithm}

The ANFIS algorithm is one of the embodiments of neurofuzzy systems (NFS), which are known as universal function approximators, useful mainly when it is necessary to model phenomena of strongly nonlinear nature and multi-dimensional functional dependencies that are difficult to determine in a purely analytical form ( $\operatorname{Ref} 22,23)$.

To determine the model of the phenomenon, fuzzy systems require much less information than traditional probabilistic 

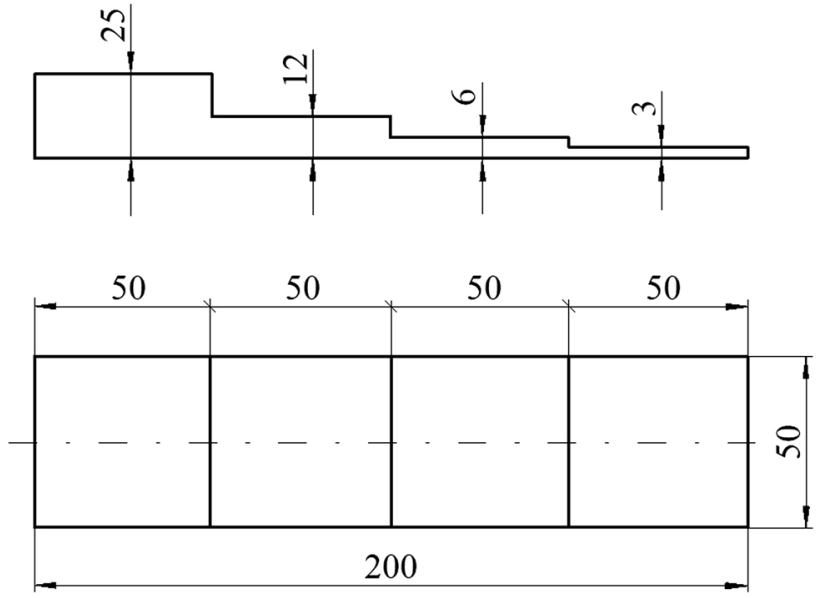

Fig. 4 Shape and dimensions of the test casting

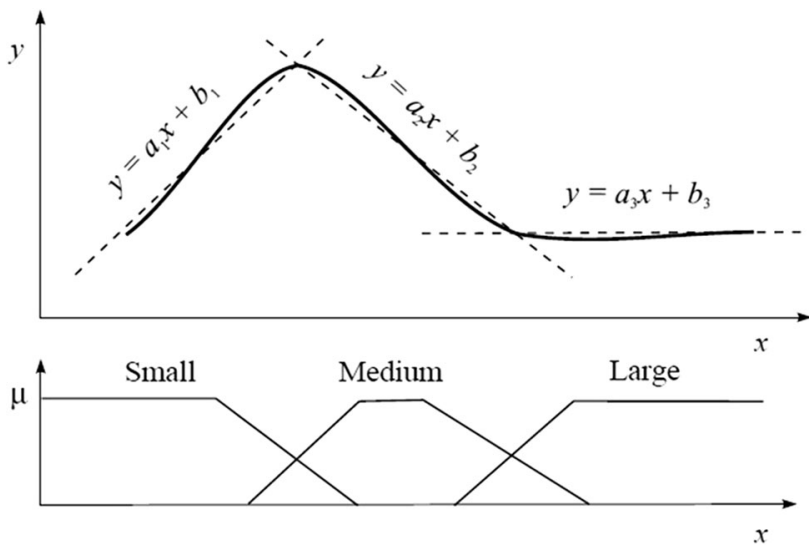

Fig. 5 General scheme illustrating the first-order SUGENO FIS model models. The information may also be imprecise, which makes ANFIS a tool for modeling very complex technological processes in which the relationship between individual factors is not known.

Within the framework of the neuro-fuzzy ANFIS algorithm, fuzzy inference systems (FIS) provide the scheme of inference, and thus the way of constructing logic rules. In the presented work, the Sugeno scheme was chosen for fuzzy inference. Its rules are characterized by first-order successors (conclusions) of the functional type (1):

If $x$ is $A 1$ then $z=f(x)$

where $x$ and $y$ are explanatory (input) variables, $A 1$ is the name of the fuzzy set representing the premise, $z$ is an explanatory variable whose value is represented by a functional linear dependence.

Based on the Sugeno model, it is possible to build a fuzzy system which, using the selected inference mechanism, makes transitions between optimal linear functions representing a narrow range of the system operation until a global system is reached; in this way it is possible to build a system of strongly nonlinear character.

Figure 5 shows a general scheme representing the mapping of three rules (2), the conclusions of which are linear functions operating within a narrow range of specific fuzzy sets. The appropriate inference mechanism adopted for the Sugeno system is able to determine the smooth transition of one function into another for areas where the sets overlap:

If $x$ is Small then $y=a_{1} x+b_{1}$

If $x$ is Medium then $y=a_{2} x+b_{2}$

If $x$ is Large then $y=a_{3} x+b_{3}$

The construction of the predictive model using the ANFIS algorithm consists in determining the FIS parameters of the system, i.e.,

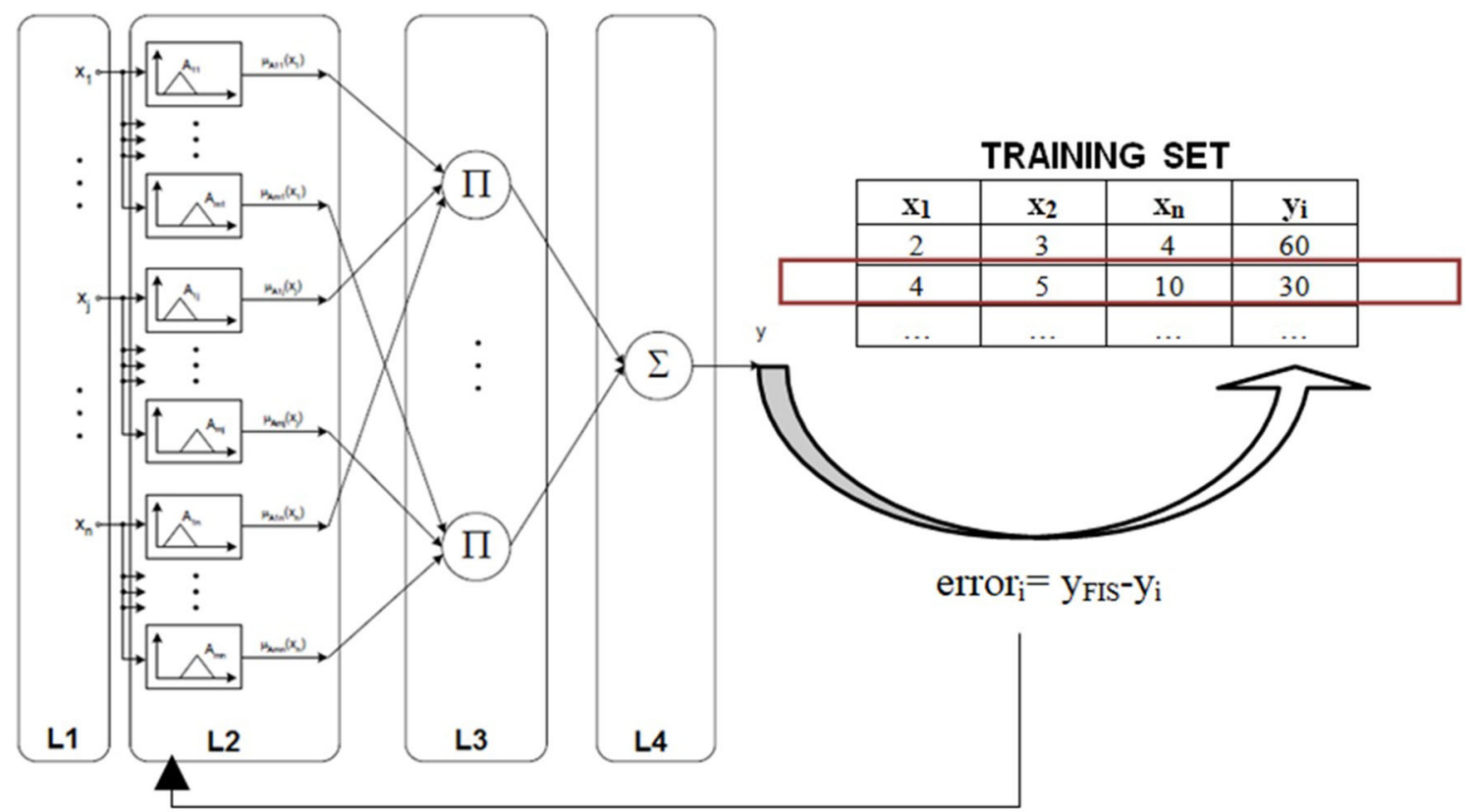

Fig. 6 Schematic representation of the ANFIS algorithm 


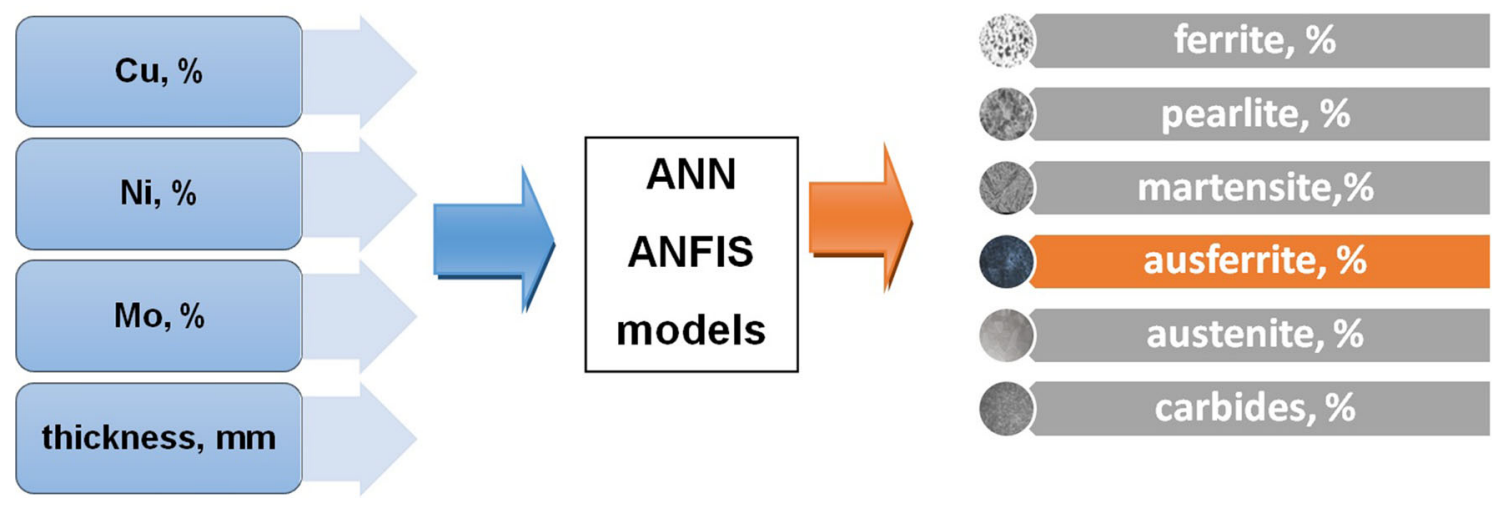

Fig. 7 List of variables in the system predicting the microstructure of compacted graphite iron

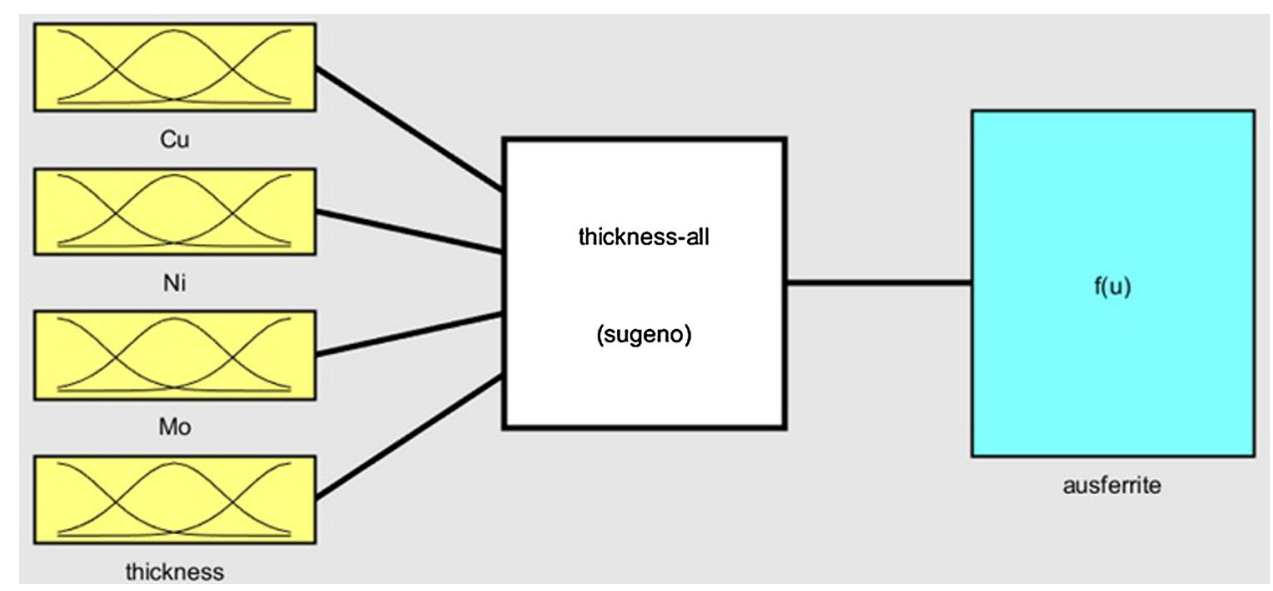

Fig. 8 AUSFERRITE - the structure of FIS model

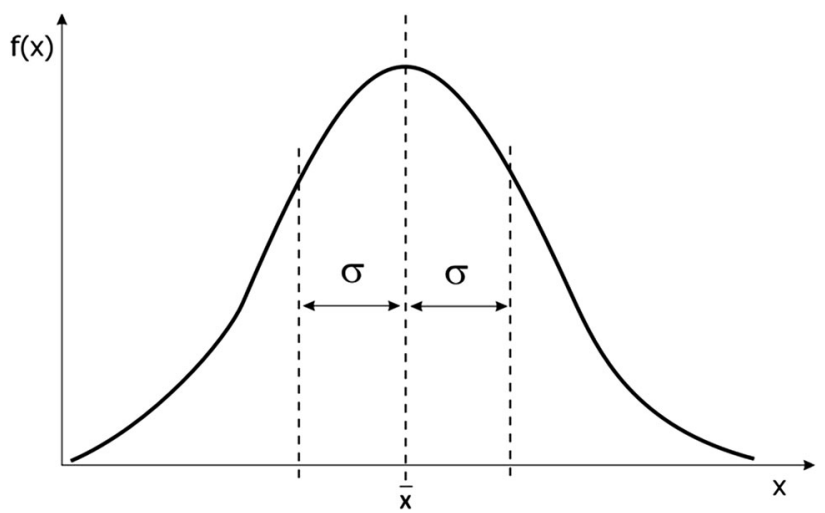

Fig. 9 Gaussian function

- fuzzy IF-THEN rules,

- parameters of the membership function of fuzzy sets for input variables,

- coefficients for determining specific linear functions in rule conclusions, based on the training data provided to the model and the use of a training algorithm taken from the theory of neural networks, the algorithm uses the optimization process with backward propagation algorithms and gradient algorithms.

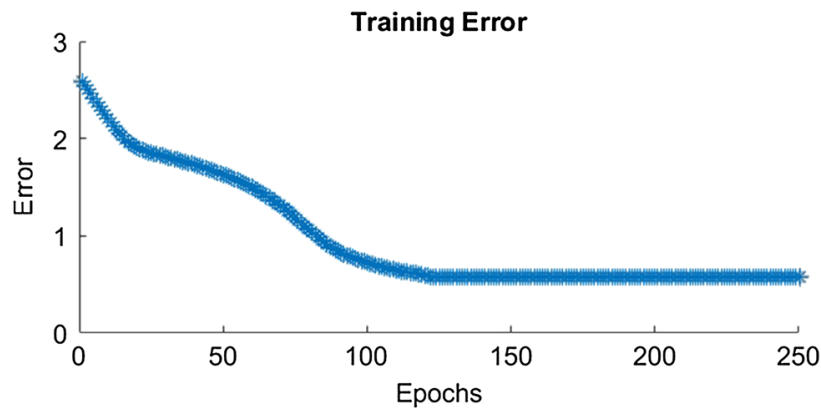

Fig. 10 Training process using the ANFIS algorithm

The process of training such a system takes place by constant changing of its parameters as a result of presenting individual case examples from the training sample. NFS training is iterative and its essence consists in adjusting the parameters of membership functions (defining the coordinates of inflection points) and determining new rule conclusions to best predict the value of the dependent variable for the tested sample. The output neuron calculates the error based on the difference between the calculated response and the correct answer given. The error is next sent to the previous layers, and the parameters of the FIS system are modified. Training stops when the average error has reached the preset minimum. 


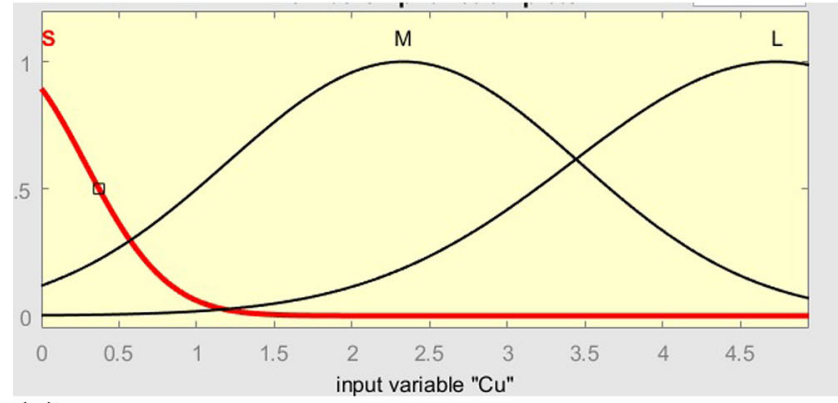

(a)

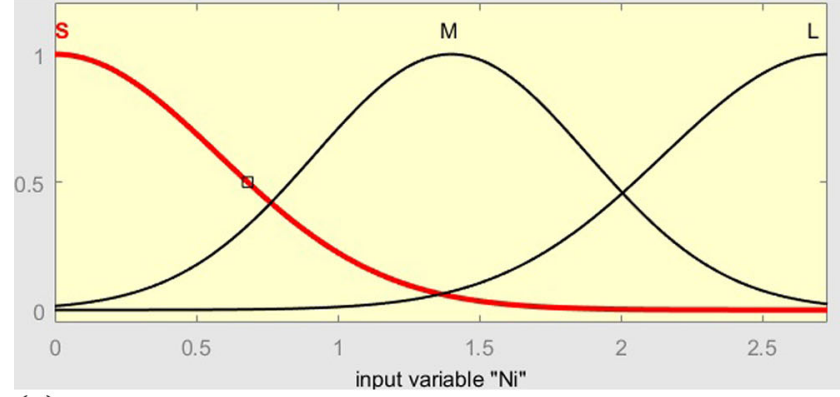

(c)

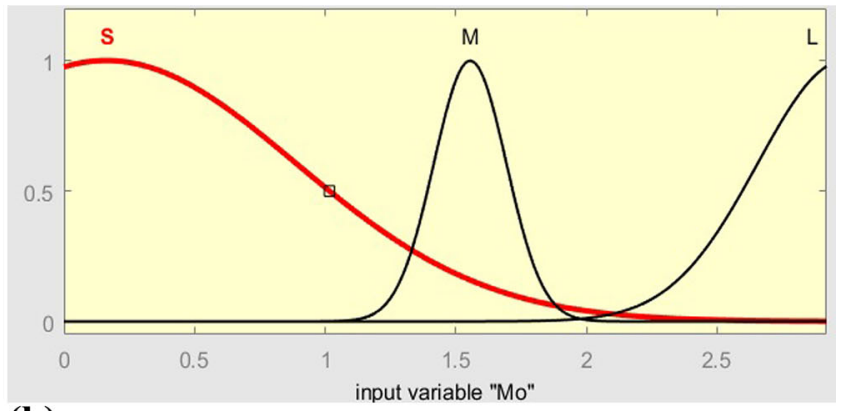

(b)

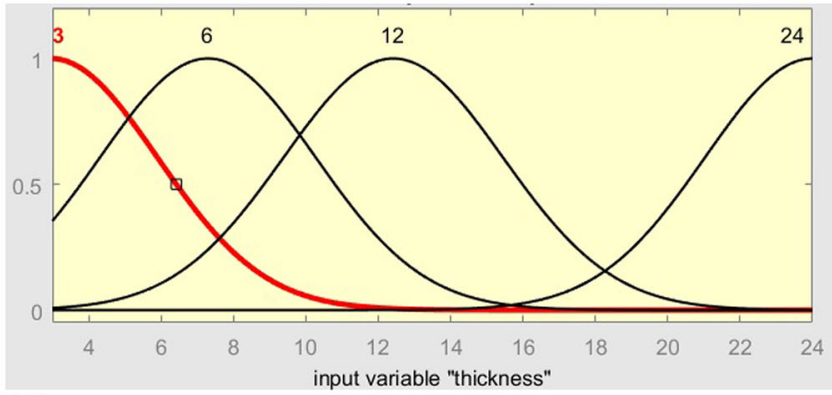

(d)

Fig. 11 Membership function plot for inputs: (a) $\mathrm{Cu}$, (b) Mo, (c) Ni and (d) thickness

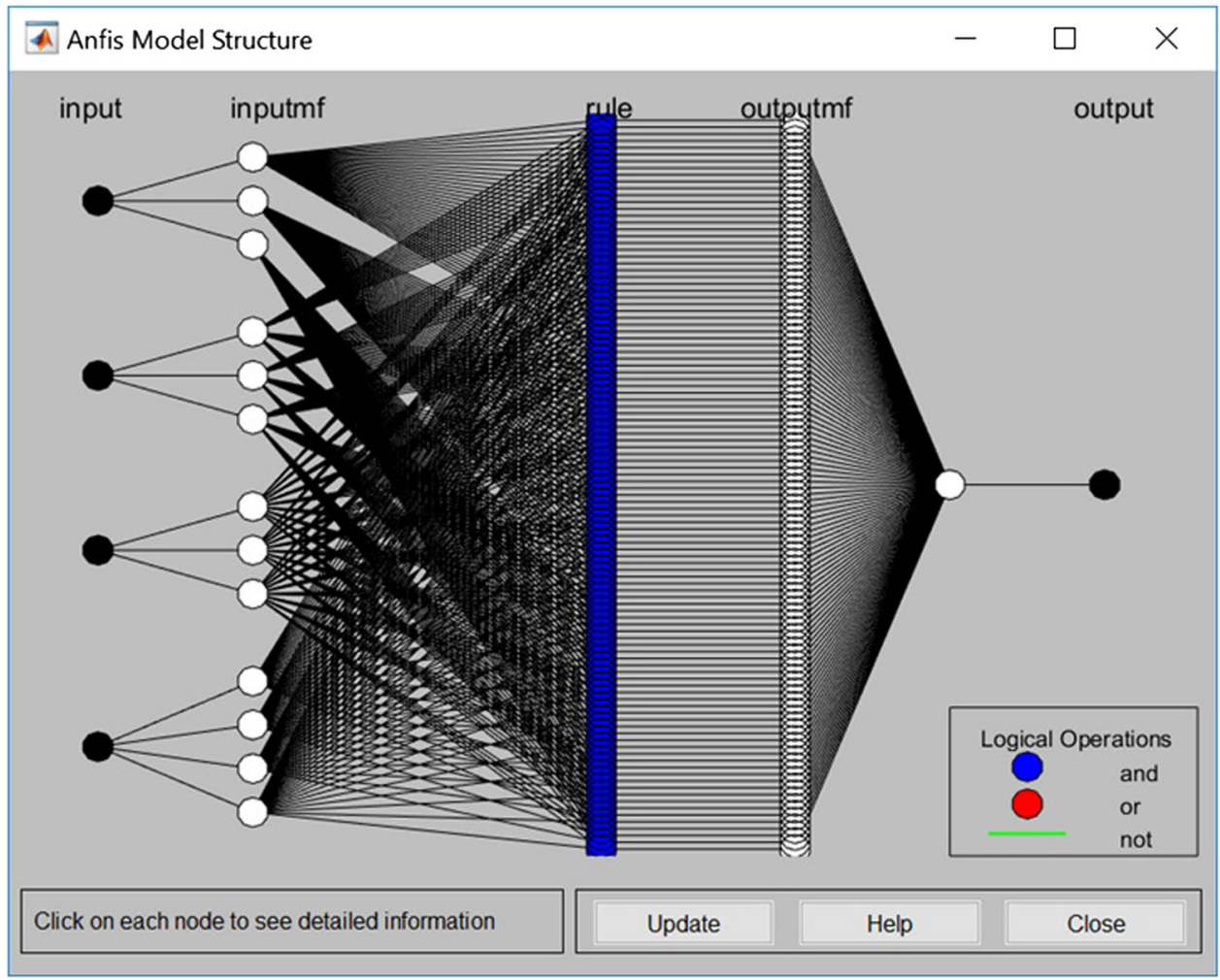

Fig. 12 The structure of the ANFIS model designed to predict the ausferrite content in a microstructure

The structure of the NFS system in the ANFIS algorithm consists of several layers. A schematic representation of the individual layers is shown in Fig. 6.

The first layer $(L 1)$ is responsible for the process of entering the values of explanatory variables from the training set $\left(x_{1}, x_{2}\right.$, $\left.\ldots, x_{n}\right)$, the second layer (L2) executes the process of blurring, i.e., determining the membership coefficients of each input vector $x_{i}$ into fuzzy sets $A_{i}^{k}$. This is done using the adopted membership functions of the input vector components, e.g., Gaussian functions (3). 


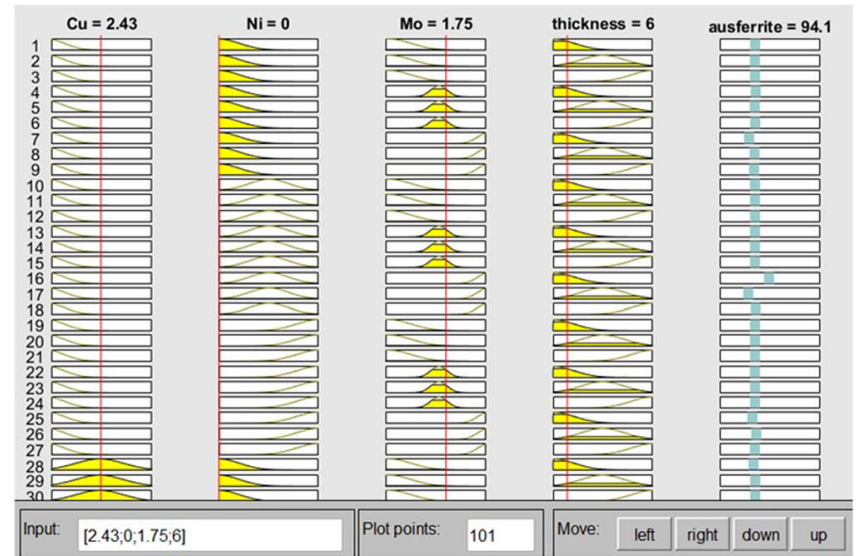

(a)

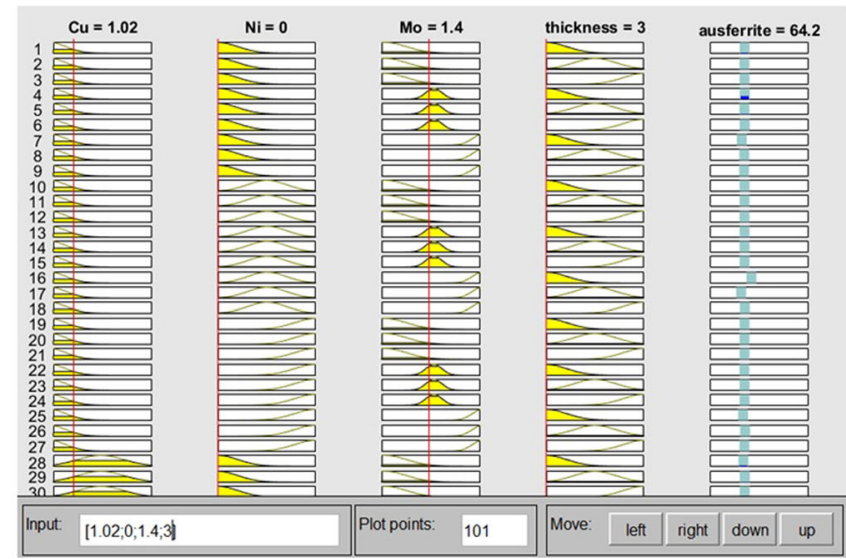

(b)

Fig. 13 Graphical representations of inference using the developed fuzzy model for inputs: (a) $\{\mathrm{Cu}=2.43, \mathrm{Ni}=0, \mathrm{Mo}=1.75$, thickness $=6\}$; (b) $\{\mathrm{Cu}=1.02, \mathrm{Ni}=0, \mathrm{Mo}=1.4$, thickness $=3\}$

$\mu_{A}(x ; \bar{x}, \sigma)=\exp \left(-\left(\frac{x-\bar{x}}{\sigma}\right)^{2}\right)$

The third layer $(L 3)$ is responsible for determining the degree of activation of the $k$-th rule $w_{k}$. Elements of this layer implement the $t$-norm, e.g., in the form of product (4):

$w_{k}(x)=\operatorname{PROD}\left[\mu_{A}(x), \mu_{B}(x)\right]$

In the next layer (L4), linear combinations of the output functions are calculated, based on the entered training data, which are then weighted by the degrees of truth of the logical rules $\left(w_{k}\right)$ and summed. At the output, the predicted value of the dependent variable is obtained for the modeled sample. Here the output from the model is compared to the pattern in the training data.

\section{The Developed Neuro-Fuzzy ANFIS System}

The developed neuro-fuzzy ANFIS system is an algorithm that enables automatic determination of parameters of the fuzzy inference system (FIS) of Sugeno type based on the training data.

In this study, the reference training cases are the results of observations and measurements of the content of individual constituents of the microstructure of compacted graphite iron (ferrite, pearlite, carbides, martensite, ausferrite and austenite) (Fig. 7). They are collected in one database and examined as a function of the content of individual alloy additives in the tested range of chemical composition, i.e.,

- $\mathrm{Cu}$ content (wt.\%),

- Ni content (wt.\%),

- Mo content (wt.\%),

- wall thickness (mm).

Due to the fact that in the course of one analysis the ANFIS algorithm can accept only one explanatory variable at the output, the process of implementing a prediction system forecasting the content of individual constituents of the microstructure as a function of the assumed concentration of alloy additives and casting wall thickness was carried out in several stages. The process involved six separate prediction models determined separately for each microstructural constituent. This study is specifically devoted to detailed presentation of a model developed for the determination of the ausferrite amount.

\subsection{The Fuzzy Model Developed for Ausferrite Using ANFIS Algorithm}

At the input to the algorithm, four input variables were given, i.e., $\mathrm{Cu}$ content, $\mathrm{Ni}$ content, Mo content and casting wall thickness (Fig. 8).

The ranges of variables defining the content of individual alloy additives have been divided into three fuzzy sets with the names \{Small, Medium, Large\}. The variable defining the casting wall thickness was divided into four fuzzy sets with the names $\{3,6,12,24\}$, representing wall thickness values that the analyzed set of training data have. All fuzzy sets have a Gaussian membership function, the formula of which is presented in Eq 3, while its general form is shown in Fig. 9.

Initially, the parameters $\bar{x}, \sigma$ of fuzzy sets are determined in a random manner. Then, in the later stages of the training algorithm operation, they are tuned based on the feedback information about the error value for the analyzed case of training vector. Tuning is done using a hybrid gradient combination of the method of the largest slope and the method of least squares.

The FIS system developed with the ANFIS algorithm works with a training error set at about 5\%; training was carried out in 125 epochs (Fig. 10). With the learning process completed, the testing process starts. It uses a test file that contains data not previously used in the network training process. The FIS system developed with the help of the ANFIS algorithm operates with a test error of about $9 \%$.

ANFIS training is iterative and its essence consists in adjusting the parameters of membership functions (e.g., width and position for the Gaussian function) to best predict the value 

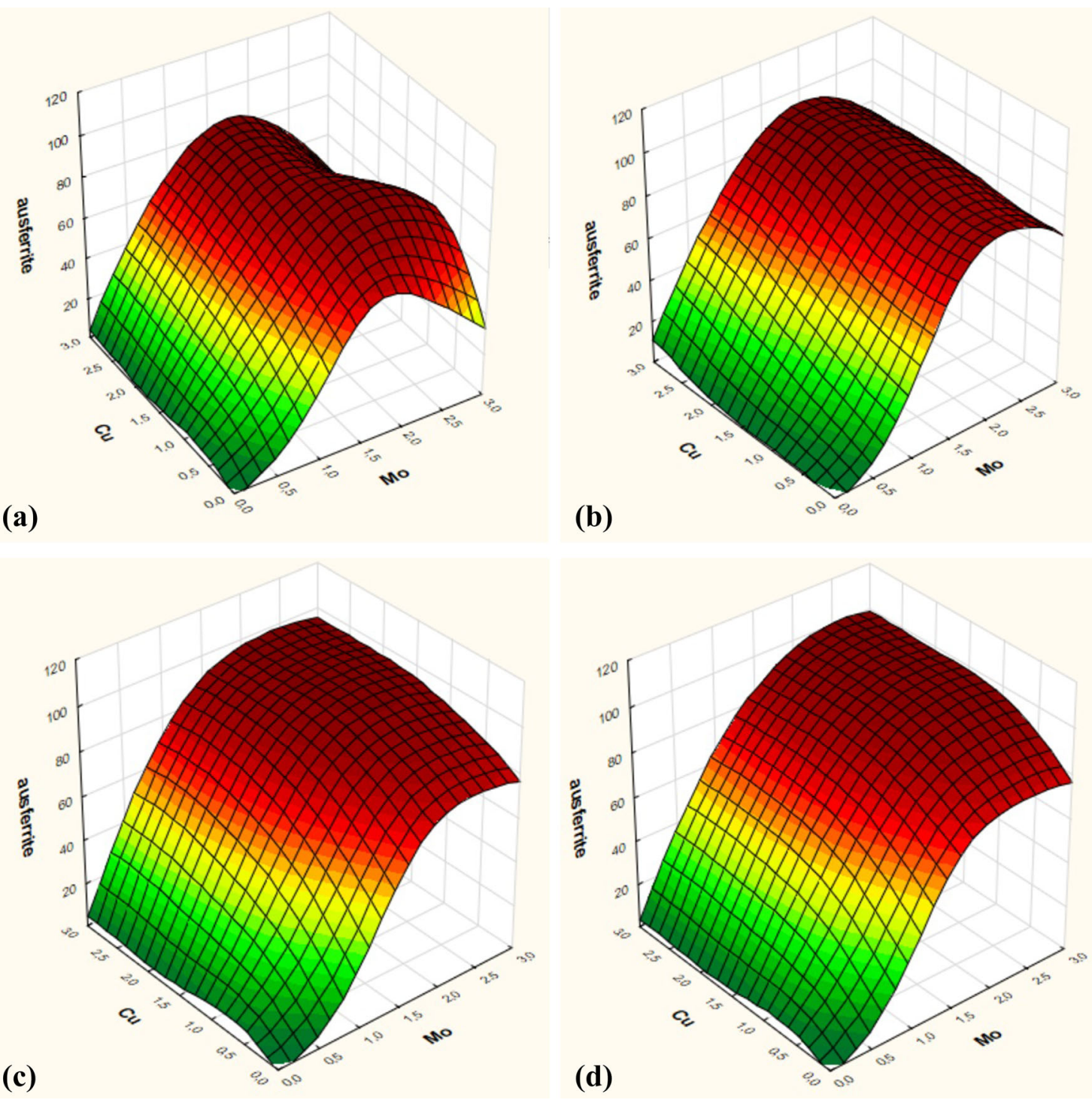

Fig. 14 The amount of ausferrite in cast iron predicted as a function of molybdenum and copper concentration in castings with the wall thickness of: (a) $3 \mathrm{~mm}$, (b) $6 \mathrm{~mm}$, (c) $12 \mathrm{~mm}$ and (d) $24 \mathrm{~mm}$

of the dependent variable for the tested sample. Figure 11 shows illustrations of fuzzy sets determined in the training process for adopted input variables.

The developed structure of the neuro-fuzzy model inference is shown in Fig. 12.

Altogether 108 subspaces were generated in the model, each of them being represented by one fuzzy rule describing the operation of the system in this sub-area. The general form of the rule is presented in formula (5), while an example of the actual rule generated by the system is given in (6).

$R^{i}: \operatorname{IF}\left(x_{1}\right.$ is $\left.A_{1}^{i}\right)$ and $\ldots$ and $\left(x_{n}\right.$ is $\left.A_{n}^{i}\right)$ THEN $\left(y=b^{i}\right)$

where $x=\left(x_{1} \ldots x_{n}\right)$ is the system input variable, $A_{j}^{i}$ are fuzzy sets, and $y \in R$ is the output variable of the system.
IF $(\mathrm{Cu}$ is $\mathrm{S})$ and $(\mathrm{Ni}$ is $\mathrm{S})$ and ( $\mathrm{Mo}$ is $\mathrm{M}$ ) and (thickness is 3) THEN

ausferrite $=822.8 \mathbf{C u}+7.893 \mathbf{N i}+79.92 \mathbf{M o}$

$$
+76.91 \text { thickness }-90.33
$$

\subsection{Inference Using the Developed Fuzzy Model}

The model developed in this article is applicable to the whole range of input variables. Figure 13 presents graphical representations of inference using the developed fuzzy model. Figure 13(a) shows the inference scenario using the developed model, where the following input variables were assumed: $\{\mathrm{Cu}=2.43, \mathrm{Ni}=0, \mathrm{Mo}=1.75$, thickness $=6\}$. The system 


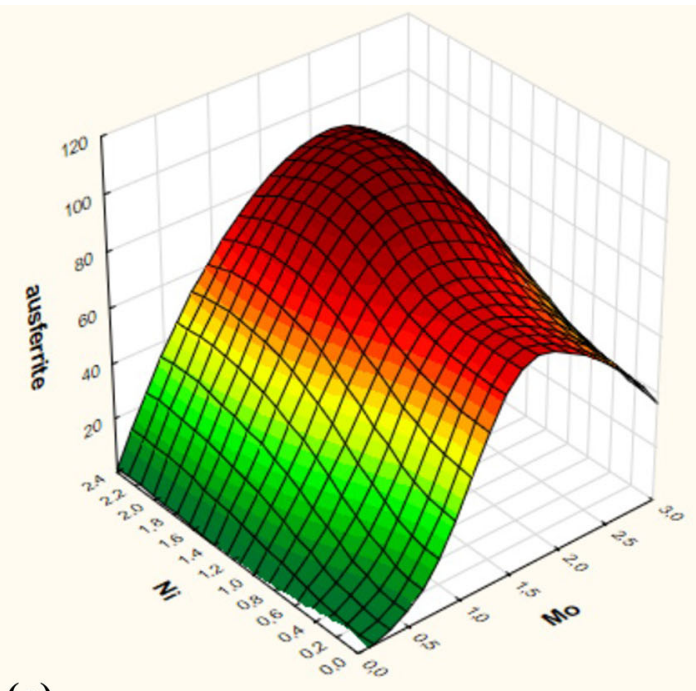

(a)

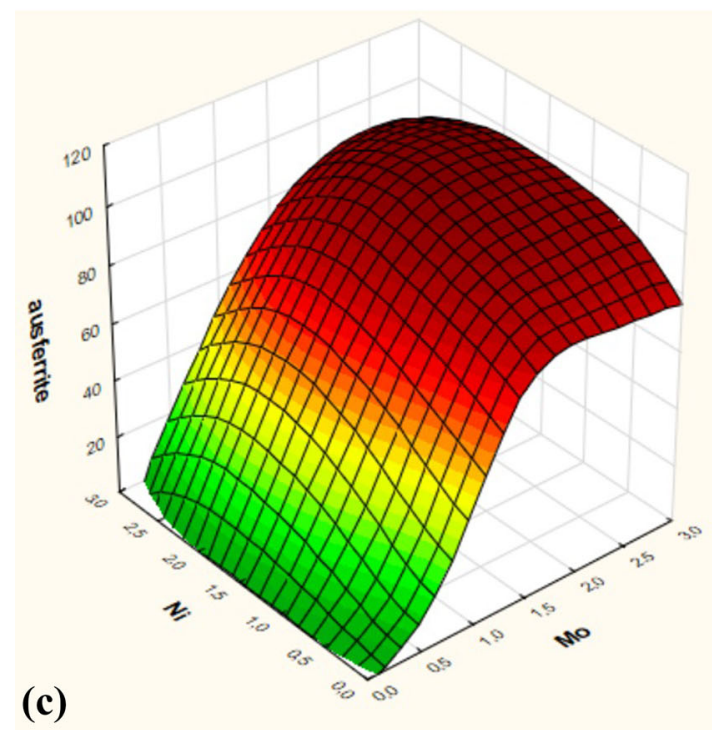

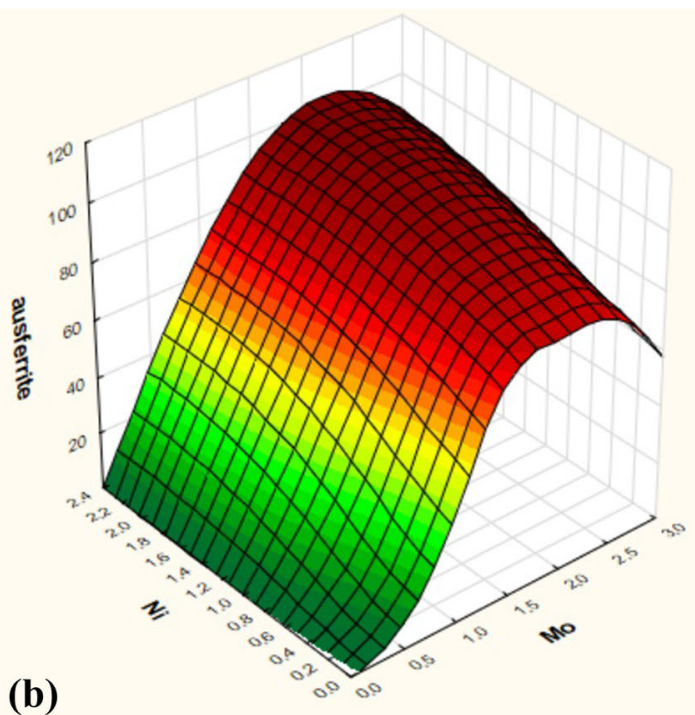

(b)

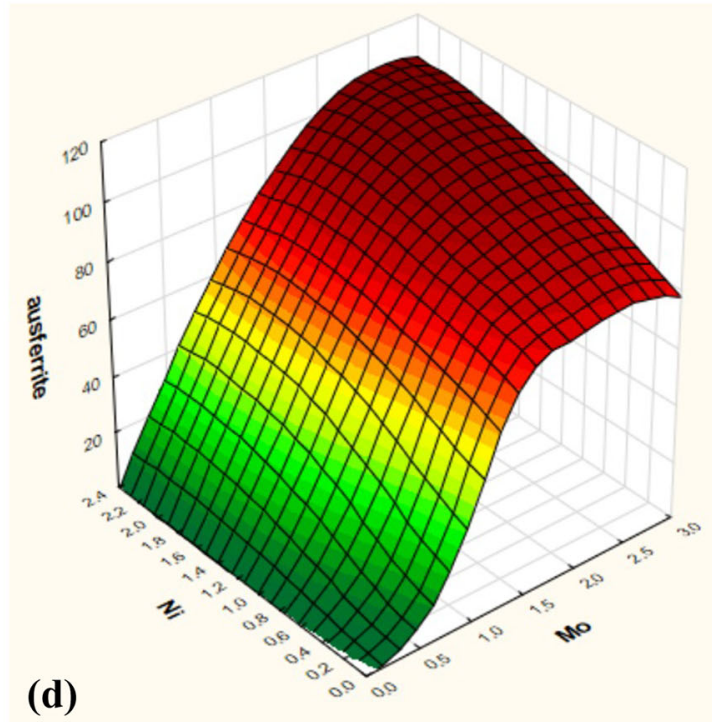

Fig. 15 The amount of ausferrite in cast iron predicted as a function of molybdenum and nickel concentration in castings with the wall thickness of: (a) $3 \mathrm{~mm}$, (b) $6 \mathrm{~mm}$, (c) $12 \mathrm{~mm}$ and (d) $24 \mathrm{~mm}$

determined the content of ausferrite at the level of $94.1 \%$, while in experimental data this value was at the level of $93 \%$. For the input values equal to $\{\mathrm{Cu}=1.02, \mathrm{Ni}=0, \mathrm{Mo}=1.4$, thickness $=3\}$, the system determined the content of ausferrite at the level of $64.2 \%$ (Fig. 13b), while in experimental data this value was at the level of $60 \%$. All tested values are within the accepted inference error of $9 \%$.

The results in the form of $3 \mathrm{D}$ sub-models, taking into account the influence of selected input variables on material consumption, are presented in Fig. 14 and 15. Figure 14(a), (b), (c), (d) and 15(a), (b), (c), (d) shows the amount of the ausferrite in cast iron predicted as a function of the concentration of molybdenum, copper and nickel in castings with the wall thickness of 3, 6, 12 and $24 \mathrm{~mm}$.

Figure 14 and 15(a), (b), (c), and (d) shows that molybdenum has the greatest influence on the formation of ausferritic microstructure in compacted graphite iron. At a concentration of about $2 \%$, it allows the formation of about $80 \%$ ausferrite in the matrix. Further increase in the amount of ausferrite is possible by adding nickel or copper into cast iron. In castings with the wall thickness of $6-24 \mathrm{~mm}$, increasing the copper concentration to about $1-1.5 \%$ results in the amount of ausferrite close to $100 \%$. In thin-walled castings, the reduction in the amount of this phase may be caused by a stronger tendency of cast iron toward crystallization in the metastable system, which means a stronger tendency to form carbides. The situation is similar as regards the addition of nickel (Fig. 15), but in this case to increase the amount of ausferrite in the matrix of cast iron to about $100 \%$ it is necessary to add $\mathrm{Ni}$ in an amount of about $1.5-2.0 \%$. The representative microstructure of CGI containing about $2 \%$ Mo and $1.5 \% \mathrm{Cu}$ obtained according to the ANFIS algorithm is presented in Fig. 16(a) and (b).

Figure 16 shows that as a result of the introduction of about $2 \% \mathrm{Mo}$ and $1.5 \% \mathrm{Cu}$ into the compacted graphite iron, a completely ausferritic matrix was obtained in castings with a wall thickness of $24 \mathrm{~mm}$ (Fig. 16b). In thin-walled castings, the content of ausferrite in the matrix is lower. This is due to a 


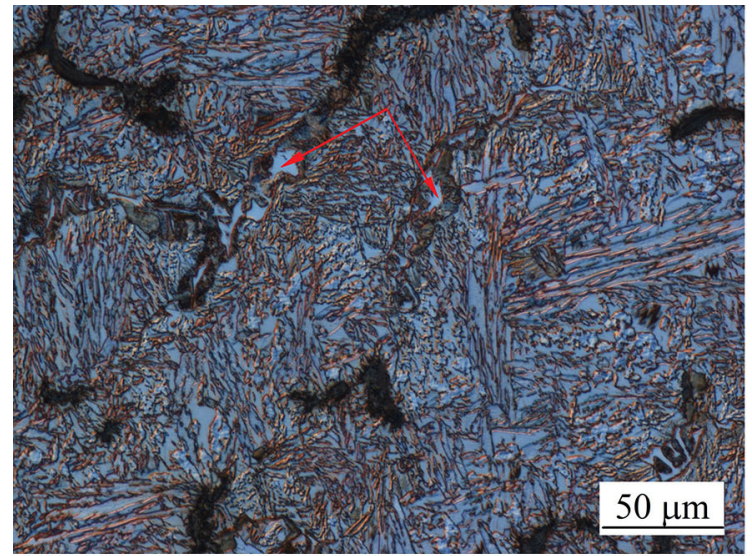

(a)

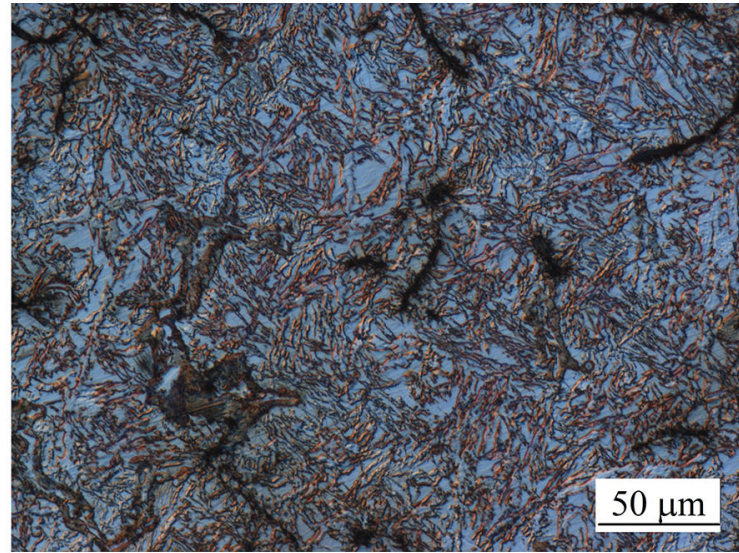

(b)

Fig. 16 The microstructure of CGI containing about $2 \% \mathrm{Mo}$ and $1.5 \% \mathrm{Cu}$ obtained according to the ANFIS algorithm in castings with the wall thickness of $3 \mathrm{~mm}$ (a) and $24 \mathrm{~mm}$ (b): compacted graphite, ausferrite and carbides (only (a)) (Color figure online)

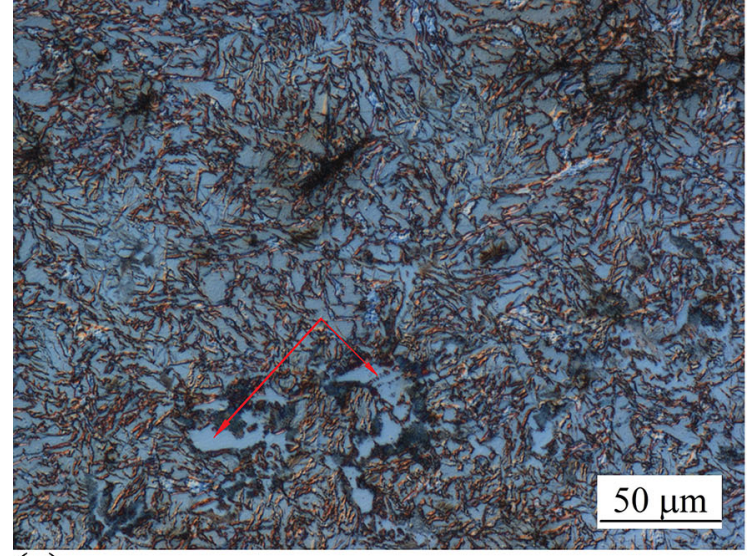

(a)

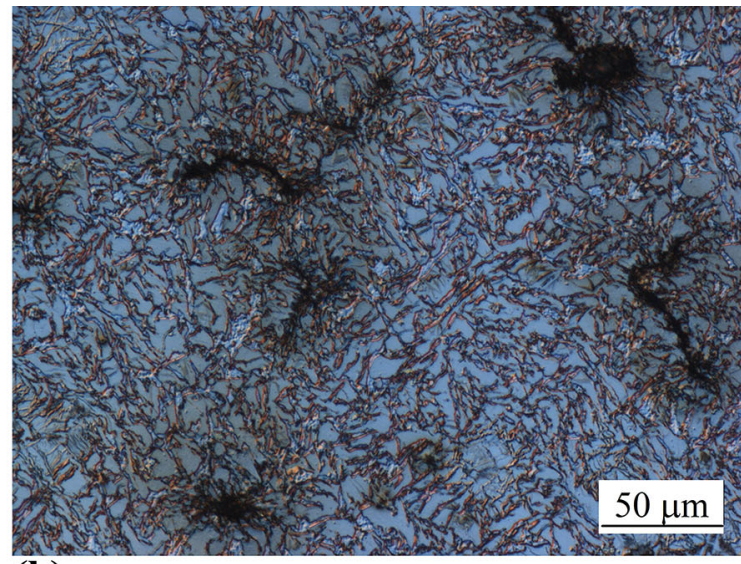

(b)

Fig. 17 The microstructure of CGI containing about 2\% Mo and 1.5\% Ni obtained according to the ANFIS algorithm in castings with the wall thickness of $3 \mathrm{~mm}$ (a) and $24 \mathrm{~mm}$ (b): compacted graphite, ausferrite and carbides (only (a)) (Color figure online)

higher cooling rate and crystallization of cast iron partly in a metastable system. The consequence is precipitation of a small amount of carbides visible in the form of light-color precipitates (marked with red arrows) (Fig. 16a). The representative microstructure of CGI containing about $2 \%$ Mo and $1.5 \% \mathrm{Ni}$ obtained according to the ANFIS algorithm is presented in Fig. 17(a) and (b).

From Fig. 17, it follows that in the compacted graphite iron containing about $2 \% \mathrm{Mo}$ and $1.5 \% \mathrm{Ni}$, the microstructure of the matrix is very similar to that shown in Fig. 16(a) and (b). It consists of ausferrite and, in the case of thin-walled castings, also of carbides (marked with red arrows) (Fig. 17a). Compared to the cast iron containing copper, the content of carbides is slightly higher, which is due to the stronger graphitizing effect of copper. The data presented in Fig. 15 and 16(a) and (b) confirm the simulation results shown in Fig. 14 and 15(a) and (b).

\section{Summary and Conclusions}

Based on the collected experimental data and using the ANFIS algorithm, it was possible to develop a predictive model that allows forecasting the content of selected constituent in the microstructure of compacted graphite iron. The FIS system developed with the help of the ANFIS algorithm operates with a test error of about $9 \%$. The results have confirmed that the proposed ANFIS model has the potential to select the chemical composition for castings made from the compacted graphite iron with high-strength properties. This will allow in the future reducing the expenditures on experimental research that mainly aims at demonstrating the possibility of producing cast iron with ausferritic microstructure of the matrix without the use of heat treatment but only by modification of its chemical composition taking into account the thickness of the casting wall. Four variables were used, i.e., $\mathrm{Mo}, \mathrm{Cu}, \mathrm{Ni}$ and casting wall thickness. The developed algorithms in the form of a ready-made program should be used in foundries producing castings made of compacted graphite iron with increased, relative to the standard grade, strength parameters and resistance to abrasion.

The conducted research also allows for a more detailed examination of the specific character of the adaptive neurofuzzy inference system (ANFIS). It enables the optimization (tuning) of fuzzy model parameters based on measurement data and allows for correction of the inaccurate fuzzy models formulated by experts. Its structure and parameters are understandable to humans (linguistic expressions, a record of 
knowledge in the form of inference rules). It enables generalization of knowledge contained in noisy measurement data and presenting it in a human-understandable form.

\section{Acknowledgments}

The study was financed under AGH Project No. 11.11.110.593.

\section{Open Access}

This article is distributed under the terms of the Creative Commons Attribution 4.0 International License (http://creativeco mmons.org/licenses/by/4.0/), which permits unrestricted use, distribution, and reproduction in any medium, provided you give appropriate credit to the original author(s) and the source, provide a link to the Creative Commons license, and indicate if changes were made.

\section{References}

1. S. Pietrowski, Compendium of Knowledge About Vermicular cast Iron, Solidif. Met. Alloys, 2000, 2(44), p 279-292 (in Polish)

2. E. Abele, A. Sahm, and H. Schulz, Wear Mechanism when Machining Compacted Graphite Iron, CIRP Ann., 2002, 51(1), p 53-56

3. T. Slatter, R. Lewis, and A.H. Jones, The Influence of Induction Hardening on the Impact Wear Resistance of Compacted Graphite Iron (CGI), Wear, 2011, 270(3-4), p 302

4. Y. Qiu, J.C. Pang, E.N. Yang, S.X. Li, and Z.F. Zhang, Transition of Tensile Strength and Damaging Mechanisms of Compacted Graphite Iron with Temperature, Mater. Sci. Eng. A, 2016, 677, p 290-301

5. M. Górny and M. Kawalec, Role of Titanium in Thin Wall Vermicular Graphite Iron Castings Production, Arch. Foundry Eng., 2013, 13(2), p 25-28

6. J.C. Pina, S. Shafqat, V.G. Kouznetsova, J.P.M. Hoefnagels, and M.G.D. Geers, Microstructural Study of the Mechanical Response of Compacted Graphite Iron: An Experimental and Numerical Approach, Mater. Sci. Eng. A, 2016, 658, p 439-449

7. D. Kopyciński, E. Guzik, A. Nowak, M. Ronduda, and M. Sokolnicki, Preparation Vermicular Graphite in Thin and Thick Wall Iron Castings, Arch. Foundry Eng., 2012, 12(2), p 41-44

8. S. Pietrowski, A mechanism of the Vermicular Graphite Crystallization in Cast Iron, Solidif. Met. Alloys, 1998, 37, p 97-104 (in Polish)

9. M.S. Soiński and P. Mierzwa, Effectiveness of Cast Iron Vermicularization Including 'Conditioning' of the Alloy, Arch. Foundry Eng., 2011, 11(2), p 133-138

10. Y. Guo, T. Stalbaum, J. Mann, H. Yeung, and S. Chandrasekar, Modulation-Assisted High Speed Machining of Compacted Graphite Iron (CGI), J. Manuf. Process., 2016, 15(4), p 426-431
11. L. Choong-Hwan and G. Byeong-Choon, Development of Compacted Vermicular Graphite Cast Iron for Railway Brake Discs, Met. Mater. Int., 2011, 17(2), p 199-205

12. P.I. Popov and I.G. Sizov, Effect of Alloying Elements on the Structure and Properties of Iron with Vermicular Graphite, Met. Sci. Heat Treat., 2006, 48(5-6), p 272-275

13. D. Wilk-Kołodziejczyk, K. Regulski, G. Gumienny, B. Kacprzyk, S. Kluska-Nawarecka, and K. Jaśkowiec, Data Mining Tools in Identifying the Components of the Microstructure of Compacted Graphite Iron Based on the Content of Alloying Elements, Int. J. Adv. Manuf. Technol., 2018, 95(9-12), p 3127-3139. https://doi.org/10.1007/s0017 0-017-1430-7

14. A. Pytel and A. Gazda, Evaluation of Selected Properties in Austempered Vermicular Cast Iron (AVCI), Trans. Foundry Res. Inst., 2014, 54(4), p 23-31. https://doi.org/10.7356/iod.2014.18

15. M.S. Soiński and A. Jakubus, Initial Assessment of Abrasive Wear Resistance of Austempered Cast Iron with Vermicular Graphite, Arch. Metall. Mater, 2014, 59(3), p 1073-1076. https://doi.org/10.2478/a $\mathrm{mm}-2014-0183$

16. A. Mavi and I. Korkut, The Effects of Austempering Temperature and Time on the Machinability of Vermicular Graphite Iron, Mater. Test., 2014, 56(4), p 289-293

17. Z. Andršová et al., The Effect of Heat Treatment on the Structure and Mechanical Properties of Austempered Iron with Vermicular Graphite, Mater. Sci. Forum, 2017, 891, p 242-248

18. J. Sertucha, P. Larrañaga, J. Lacaze, and M. Insausti, Experimental Investigation on the Effect of Copper Upon Eutectoid Transformation of As-Cast and Austenitized Spheroidal Graphite Cast iron, Int. J. Metalcast., 2010, 10, p 51-58

19. G. Gumienny, B. Kurowska, T. Szymczak, and J. Gawroński, Nickel in Compacted Graphite Iron, Arch. Metall. Mater, 2017, 62(3), p 657662. https://doi.org/10.1515/amm-2017-0096

20. M. Ferry and W. Xu, Microstructural and Crystallographic Features of Ausferrite in As-Cast Gray Iron, Mater. Charact., 2004, 53(1), p 4349. https://doi.org/10.1016/j.matchar.2004-.07.008

21. G. Gumienny, L. Klimek, and B. Kurowska, Effect of the Annealing Temperature on the Microstructure and Properties of Ausferritic Nodular Cast Iron, Arch. Foundry Eng., 2016, 16(Special Issue 3), p $43-48$

22. G. Gumienny and B. Kacprzyk, Copper in Ausferritic Compacted Graphite Iron, Arch. Foundry Eng., 2018, 18(1), p 162-166

23. J.S.R. Jang, ANFIS: Adaptive-Network-Based Fuzzy Inference System, IEEE Trans. Syst. Man Cybern., 1993, 23(3), p 665-685

24. M. Hawryluk, B. Mrzygłód, Application of Adaptive Neuro-Fuzzy Inference System (ANFIS) to Predict the Wear of Forging Tools, METAL 2016: 25th International Conference on Metallurgy And Materials, 2016, p. 384-385

25. S.P. Lo, An Adaptive-Network Based Fuzzy Inference System for Prediction of Workpiece Surface Roughness in End Milling, J. Mater. Process. Technol., 2003, 142(3), p 665-675

Publisher's Note Springer Nature remains neutral with regard to jurisdictional claims in published maps and institutional affiliations. 